\title{
Performance of the high-strength self-stressing and self-compacting concrete-filled steel tube columns subjected to the uniaxial compression
}

\author{
Lihua $\mathrm{Xu}^{1}, \quad$ Penghua Zhou ${ }^{1}, \quad{\text { Yin } \mathrm{Chi}^{1 *}}^{*}, \quad$ Le Huang ${ }^{1}, \quad$ Jianqiao $\mathrm{Ye}^{2}, \quad$ Min $\mathrm{Yu}^{1}$ \\ ${ }^{1}$ School of Civil Engineering, Wuhan University, No. 8 Dong Hu South Road, Wuhan, 430072, China \\ ${ }^{2}$ Engineering Department, Lancaster University, Lancaster, UK
}

\section{Highlights:}

1. The effects of self-stress on the uniaxial compression of concrete filled steel tube column were investigated;

2. Favorable improvements in the ultimate bearing capacity of HSS-CFST columns were observed;

3. Analytical predictions for evaluating the compressive bearing capacity of HSS-CFST columns were proposed.

\begin{abstract}
In order to improve the compactness of concrete and prevent the debonding between steel tube and concrete core, a high-strength self-stressing and self-compacting concrete-filled steel tube (HSS-CFST) column is introduced. This paper deals with an experimental study on the uniaxial compression of HSS-CFST. A total of 51 specimens subjected to axial compression were investigated. Important variables, including self-stress level, concrete strength, tube thickness, and length-to-diameter ratio, were studied. The failure modes, ultimate bearing capacity and post-peak ductility were analyzed. The results showed that, the use of HSS concrete in CFST yielded a better uniaxial compression performance in comparison with conventional CFST specimens. An increase of $12.4 \%$ in ultimate bearing capacity was observed for a HSS-CFST specimen having a self-stress of $5 \mathrm{MPa}$. The improvement becomes more pronounced as the length-to-diameter ratio increases. Besides, increasing concrete strength can also contribute significantly to the ultimate bearing capacity, whilst improvement on the post-peak ductility is not obvious. Furthermore, a numerical analysis considering the self-stressing was carried out, which provided a good agreement between the experimental results. Finally, predictive equations specially to calculating the ultimate bearing capacity of HSS-CFST columns are proposed and then validated by the experimental results.
\end{abstract}

Keywords: uniaxial compression performance; high-strength; self-stress; concrete-filled steel tube

\section{Introduction}

Over the last few decades, the concrete-filled steel tubes (CFST), especially the high-strength CFST column, have been widely used in the construction of high-rise buildings and long-span bridges, for its excellent mechanical properties and constructional efficiency [1]. Among the common applications, a CFST column in practice is mostly subjected to high axial compression loads, under which the outer steel tube continuously provides a uniform confining pressure on the concrete core, while the inner concrete in turn can effectively prevent or delay the local buckling of steel tube [2]. By means of such an interactive action, the composite member optimizes the advantages of both materials, and therefore manifests preferable performances, like higher ultimate bearing capacity, enhanced 
ductile seismic response, and better fire resistance than hollow steel or reinforced concrete structures [3]. Furthermore, from the viewpoint of construction, the outer steel tube can serve as the formwork for concreting, which will greatly expedite construction speed, and bring in considerable economic benefits eventually [4].

To date, extensive studies have been conducted to investigate the compression performance of high-strength CFST columns [5-11]. The test results from Rangan et al. [5] showed that in comparison with the normal-strength CFST column, the use of high-strength concrete in CFST could further maximize the mechanical properties. More recently, the investigation from Liang [6] evidenced that increasing concrete strength would lead to remarkable increases in stiffness, axial load and moment capacities. Similar observations were also reported by Varma et al. [7] and Liu et al. [8,9]. However, the debonding between the steel tube and concrete core, mainly resulted from the shrinkage and deformation difference, exerts a great adverse influence on the aforementioned synergistic confinement, and significantly reduces the ultimate bearing capacity and post-peak ductility [12]. This situation is even worse for the high-strength CFST column because of the much more brittle infilled concrete [4]. Hence, any improvement enabling tackle this weakness is expected to be benificial.

A comprehensive literature review shows that the introduction of expansive agents into cement is able to compensate the concrete shrinkage fairly well, and even prestress the outer formwork during the curing time [13-15]. Inspired by this, some attempts therefore were made to replace the conventional concrete with self-stressing concrete [16], and the experimental results from Chang et al. [17,18] suggested that the self-stressing CFST was a promising alternative because of its constructive capacity in reducing the unfavorable effects caused by debonding. However, of the limited researches concerning this, the majority of interests, to the authors' best knowledge, were concentrated on the study of bond behavior, shear resistance and bending capacity, while the uniaxial compression performance has not been well documented so far.

To this end, the focus of this paper is mainly placed on the investigation of the uniaxial compression performance of high-strength self-stressing and self-compacting concrete-filled steel tube (HSS-CFST), considering the influences of self-stress level, concrete strength, tube thickness, and length-to-diameter ratio. From these investigation and the existing code, an empirical formula considering the positive effect of self-stress was proposed to calculate the ultimate bearing capacity of HSS-CFST, which were then validated by the experimental results.

\section{Experimental program and setup}

\subsection{Materials}

As the mix proportions shown in Table 1 , seven concrete mixtures were designed, in which the Ordinary Portland cement (P.O. 52.5) was used as the binder, the normal river sand with a fineness modulus of 2.6 was used as the fine aggregates, and the crushed granitic gravels of sizes between $5 \mathrm{~mm}$ and $20 \mathrm{~mm}$ were used as the coarse aggregates. To obtain the expected grades of concrete strength $(\mathrm{C} 60, \mathrm{C} 70, \mathrm{C} 80)$ and self-stress $(0,3,5 \mathrm{MPa})$, additional mineral admixtures, like fly ash, slag, silica fume and microspheres, with different dosages were introduced into the mixture, respectively. Furthermore, a highly efficient water reducing agent with a reducing rate of about $25 \%$ was also adopted in order to improve the workability.

The 28 day compressive strength of the mixture are listed in Table 3. 
Table 1

Designed mix proportions of concrete $\left(\mathrm{kg} / \mathrm{m}^{3}\right)$

\begin{tabular}{ccccccccccc}
\hline Notation & Cement & Sand & Gravel & Water & Fly ash & Slag & $\begin{array}{c}\text { Silica } \\
\text { fume }\end{array}$ & $\begin{array}{c}\text { Micro } \\
\text { spheres }\end{array}$ & $\begin{array}{c}\text { Expansion } \\
\text { agent }\end{array}$ & $\begin{array}{c}\text { Super } \\
\text { plasticizer }\end{array}$ \\
\hline C1S0 & 336 & 750 & 950 & 150 & 84 & 84 & - & 56 & - & 11.20 \\
C1S1 & 336 & 750 & 950 & 150 & 28 & 84 & - & 56 & 56 & 11.20 \\
C1S2 & 336 & 750 & 950 & 146 & 30 & 60 & - & 56 & 78 & 11.20 \\
C2S1 & 380 & 750 & 950 & 138 & 86 & 34 & 40 & - & 60 & 13.80 \\
C2S2 & 380 & 750 & 950 & 138 & 86 & 22 & 40 & - & 72 & 13.80 \\
C3S1 & 410 & 750 & 950 & 135 & 100 & 10 & 48 & - & 62 & 17.64 \\
C3S2 & 410 & 750 & 950 & 135 & 100 & - & 46 & - & 74 & 17.64 \\
\hline
\end{tabular}

Table 2 gives the characteristic properties of steel tubes. All the details satisfied the requirements of codes GB/T 228-2002 [19].

Table 2

Properties of steel tubes.

\begin{tabular}{ccccccc}
\hline \multirow{2}{*}{ Notation } & Dimension & Elastic modulus & Yielding strength & Ultimate strength & Poisson's ratio & \multicolumn{2}{c}{ Elongation } \\
& $D \times t(\mathrm{~mm})$ & $E_{s}(\mathrm{MPa})$ & $f_{y}(\mathrm{MPa})$ & $f_{u}(\mathrm{MPa})$ & $v_{s}$ & $\delta(\%)$ \\
\hline T1 & $159 \times 3.14$ & $2.03 \times 10^{5}$ & 345.54 & 467.26 & 0.271 & 24.5 \\
T2 & $159 \times 3.92$ & $1.99 \times 10^{5}$ & 367.35 & 484.96 & 0.275 & 24.7 \\
T3 & $159 \times 4.68$ & $2.05 \times 10^{5}$ & 346.79 & 470.63 & 0.286 & 24.2 \\
\hline
\end{tabular}

Note: $1 . D, t$ represent the outer diameter and thickness of the steel tube, respectively.

2. $\delta=\left[\left(L_{u}-L_{0}\right) / L_{0}\right] \times 100 \%$, where $L_{0}, L_{u}$ are the initial and elongated length of the tested steel sheets.

\subsection{Specimens preparation}

A total of 51 CFST columns (17 groups) were tested, including two control groups. As illustrated in Fig. 1, all the specimens were fabricated from seamless circular steel tubes having an identical outer diameter of $159 \mathrm{~mm}$, while the thickness of tubes were $3.14,3.92$, and $4.68 \mathrm{~mm}$, respectively, to achieve different levels of lateral confinement. To investigate the influence of length-to-diameter ratio on the uniaxial compression performance, five cases, i.e. $L / D=3,5,8,10$ and 12 , were considered.

The specimens were cast in a vertical position and the concrete was infilled without any vibrations. After casting, the specimens were stored in the curing room at a constant temperature of $20^{\circ} \mathrm{C}$ for 28 days. In addition, for each group, three cubes of $150 \mathrm{~mm}$ side length were prepared from the same batch mixture for compressive strength tests.

The variables considered in this test are summarized in Table 3. 

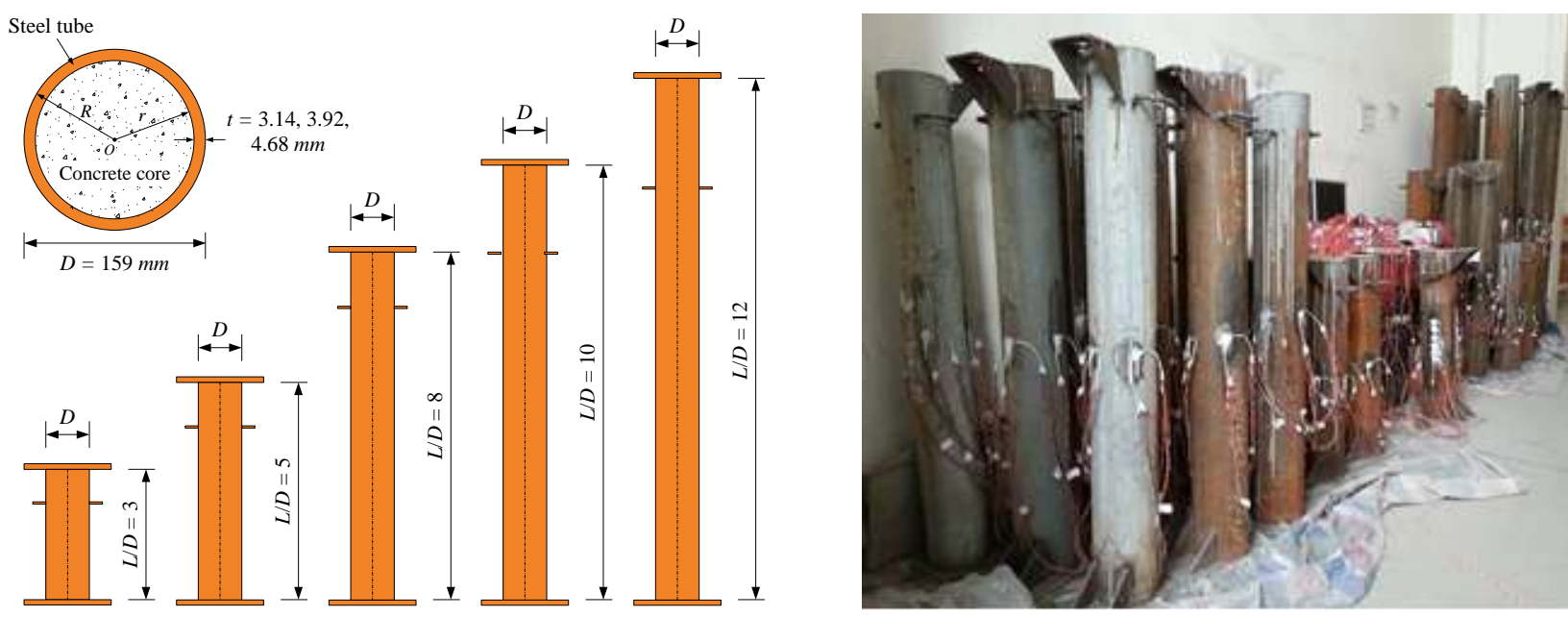

Fig. 1 Dimension of specimens and the site view.

Table 3

Details of the specimens

\begin{tabular}{|c|c|c|c|c|c|c|c|c|c|c|}
\hline \multirow{2}{*}{ No. } & \multirow{2}{*}{ Specimen } & \multicolumn{4}{|c|}{ Steel tube } & \multicolumn{3}{|c|}{ Concrete } & \multirow{2}{*}{$\begin{array}{c}\text { Slenderness } \\
L / D\end{array}$} & \multirow{2}{*}{$\begin{array}{c}\text { Confinement } \\
\text { factor } \xi\end{array}$} \\
\hline & & $t(\mathrm{~mm})$ & $f_{y}(\mathrm{MPa})$ & $\varepsilon_{z}(\mu \varepsilon)$ & $\varepsilon \theta(\mu \varepsilon)$ & $f_{c u}(\mathrm{MPa})$ & $f_{c}(\mathrm{MPa})$ & $\sigma_{r}(\mathrm{MPa})$ & & \\
\hline 1 & C1-S1-T1-L1 & 3.14 & 345.54 & 191.42 & 308.93 & 64.80 & 52.88 & 3.28 & 3 & 0.548 \\
\hline 2 & C1-S1-T2-L1 & 3.92 & 367.35 & 192.28 & 246.39 & 64.80 & 52.88 & 3.34 & 3 & 0.739 \\
\hline 3 & C1-S1-T3-L1 & 4.68 & 346.79 & 172.02 & 225.78 & 64.80 & 52.88 & 3.84 & 3 & 0.846 \\
\hline 4 & C1-S1-T2-L2 & 3.92 & 367.35 & 179.13 & 277.78 & 64.80 & 52.88 & 3.65 & 5 & 0.739 \\
\hline 5 & C1-S1-T2-L3 & 3.92 & 367.35 & 173.12 & 245.38 & 64.80 & 52.88 & 3.27 & 8 & 0.739 \\
\hline 6 & C1-S1-T2-L4 & 3.92 & 367.35 & 165.70 & 239.36 & 64.80 & 52.88 & 3.18 & 10 & 0.739 \\
\hline 7 & C1-S1-T2-L5 & 3.92 & 367.35 & 173.15 & 257.92 & 64.80 & 52.88 & 3.41 & 12 & 0.739 \\
\hline 8 & C1-S2-T2-L1 & 3.92 & 367.35 & 237.59 & 334.28 & 65.20 & 53.20 & 4.46 & 3 & 0.735 \\
\hline 9 & C1-S2-T2-L3 & 3.92 & 367.35 & 227.88 & 423.86 & 65.20 & 53.20 & 5.43 & 8 & 0.735 \\
\hline 10 & C2-S1-T2-L1 & 3.92 & 367.35 & 175.16 & 235.86 & 77.99 & 63.64 & 3.17 & 3 & 0.614 \\
\hline 11 & C2-S1-T2-L3 & 3.92 & 367.35 & 151.56 & 236.98 & 77.99 & 63.64 & 3.11 & 8 & 0.614 \\
\hline 12 & C2-S2-T2-L1 & 3.92 & 367.35 & 198.45 & 292.18 & 79.42 & 64.81 & 3.87 & 3 & 0.603 \\
\hline 13 & C3-S1-T2-L1 & 3.92 & 367.35 & 162.12 & 260.95 & 88.33 & 72.08 & 3.41 & 3 & 0.542 \\
\hline 14 & C3-S1-T2-L3 & 3.92 & 367.35 & 161.77 & 270.01 & 88.33 & 72.08 & 3.51 & 8 & 0.542 \\
\hline 15 & C3-S2-T2-L1 & 3.92 & 367.35 & 190.08 & 298.96 & 88.86 & 72.51 & 3.92 & 3 & 0.539 \\
\hline 16 & C1-S0-T2-L1 & 3.92 & 367.35 & 0 & 0 & 66.90 & 57.59 & 0 & 3 & 0.716 \\
\hline 17 & C1-S0-T2-L3 & 3.92 & 367.35 & 0 & 0 & 66.90 & 57.59 & 0 & 8 & 0.716 \\
\hline
\end{tabular}

Note: Confinement factor $\xi$ is the ratio of the bearing capacity between steel tube and concrete core, i,e, $\xi=\left(A_{s} f_{y}\right) /\left(A_{c} f_{c}\right)$.

\subsection{Test setup and loading procedure}

The uniaxial compression tests were conducted on a universal testing machine. The details of the test setup and instrumentations are schematically shown in Fig. 2. The axial loading was provided by the vertical hydraulic pressure servo-actuator, with a maximum bearing capacity of $5000 \mathrm{kN}$. Two linear variable differential transducers (LVDTs) were used to measure the relative vertical shortening of the specimen, and another three LVDTs were mounted at the $1 / 4,1 / 2$, and $3 / 4$ height of the specimen to measure the lateral deflections. Besides, eight strain gauges were glued at the mid-height of steel tube to measure the hoop and axial strain. 

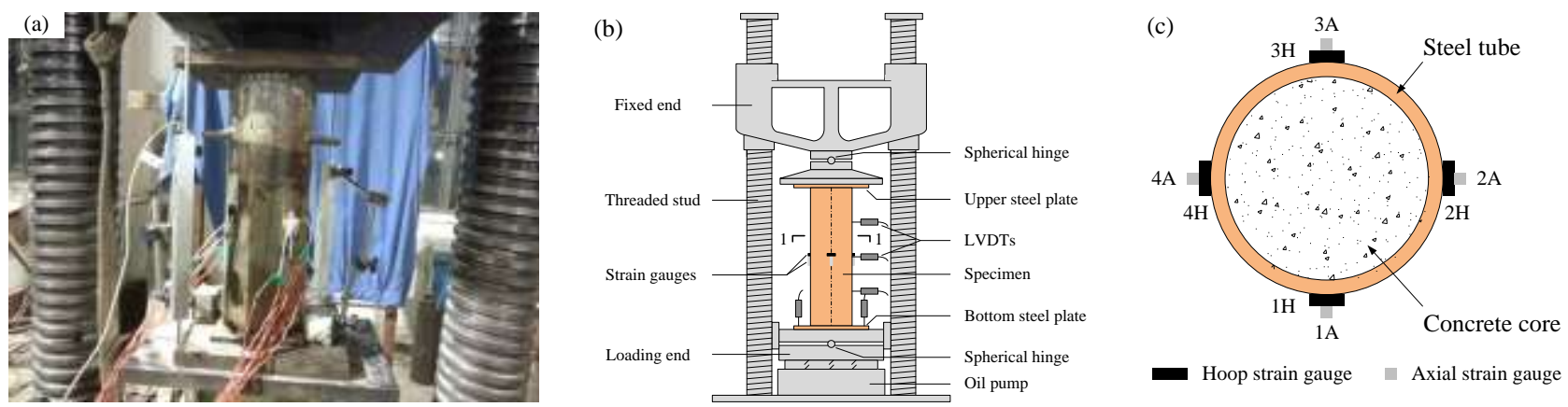

Fig. 2 The schematic of test setup and details of instrumentations.

In order to minimize the axial eccentricity, an initial compression was imposed to ensure that no significant eccentricity occurred at the beginning of the tests. This was performed by checking the reading of the LVDTs and fine-adjusting the position of the specimen. Subsequently, a predetermined axial loading procedure as sketched in Fig. 3 was carried out. Before reaching the peak strength, the increment of load at each step was about 1/10 of estimated ultimate bearing capacity, and the load interval was 4 minutes. However, around the peak state, the load increment was decreased to $1 / 20$ of the ultimate bearing capacity, and the interval was maintained for about 2 minutes. After that, the load was slowly reduced to about $80 \%$ of the ultimate bearing capacity, when the test was completed.

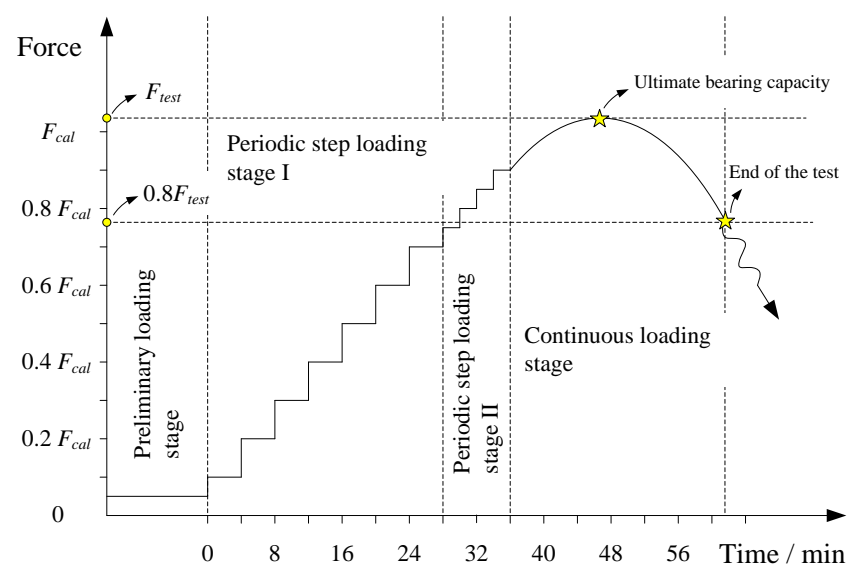

Fig. 3 Loading procedure.

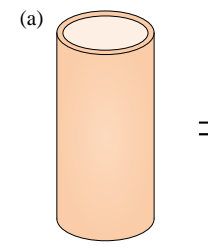

HSS-CFST

Stress analysis: (b)

Note:

(a) Decomposition of HSS-CFST; (b) stress state of steel tube; (c) stress state of concrete.

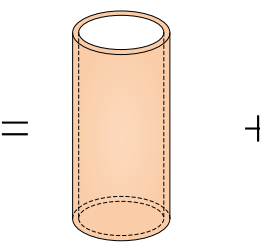

Steel tube

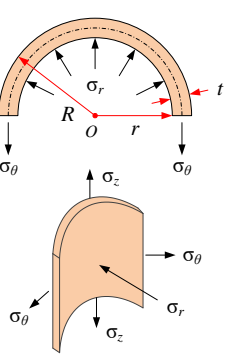

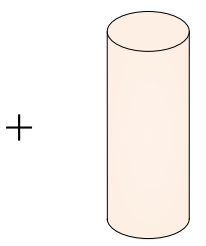

Concrete core

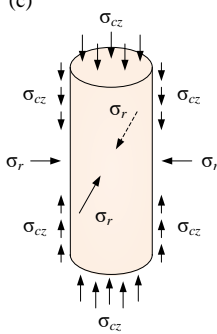

Fig. 4 Force decomposition diagram of HSS-CFST.

\subsection{Calculation of self-stresses}

In the process of stress analyses, the HSS-CFST is decomposited into two parts, i.e. the steel tube and the concrete core, as shown in Fig. 4 (a). According to the third law of Newtonian mechanics, the self-stresses in the concrete core can be indirectly calculated by means of the expansive strains of the outer steel tube.

For simplicity, the steel tube is thought to be subjected to a biaxial state of stress, as depicted in Fig. 4 (b). So, according to the generalized Hook law, the self-stresses can be calculated as follows

$\sigma_{\theta}=\frac{E_{s}}{1-v_{s}^{2}}\left(\varepsilon_{\theta}+v_{s} \varepsilon_{z}\right)$ 
$\sigma_{z}=\frac{E_{s}}{1-v_{s}^{2}}\left(\varepsilon_{z}+v_{s} \varepsilon_{\theta}\right)$

where $\sigma_{\theta}, \sigma_{z}$ are the hoop and axial stresses in steel tube, respectively; $\varepsilon_{\theta}, \varepsilon_{z}$ are the ultimate hoop and axial strains obtained from the strain gauges glued on the outer side of the steel tube, respectively; $E_{s}, v_{s}$ are the modulus of elasticity and Poisson's ratio of steel, respectively.

In accordance with the equilibrium condition of forces, the radial self-stress $\sigma_{r}$ in the concrete core can be evaluated as

$2 \sigma_{\theta} t=2 r \sigma_{r} \Rightarrow \sigma_{r}=\frac{t}{r} \sigma_{\theta}$

and the axial self-stress $\sigma_{c z}$ in the concrete core reads as,

$\sigma_{c z} A_{c}=\sigma_{z} A_{s} \Rightarrow \sigma_{c z}=\frac{2 t}{r} \sigma_{z}$

where $t$ is the thickness of the steel tube, and $r$ is the inside radius of the steel tube.

Due to that the fundamental objective of this work is to increase the steel confinement using self-stressing concrete, the axial self-stress $\sigma_{c z}$ is not considered hereinafter, and the radial self-stresses $\sigma_{r}$ for all the specimens are summarized in Table 3.

\section{Experimental results}

\subsection{Experimental observations}

During the initial loading stage, similar to the conventional CFST columns, no obvious change in the appearance of the HSS-CFST specimens was found, and the axial deformation was approximately proportional to the axial load. It was until almost reaching the maximum load that some local bucklings could be observed on the steel tube face. Compared with buckling failure of hollow steel columns, the HSS-CFST specimens herein mainly failed with outward bucklings, and the locations were not restricted at the mid-height. An elephant foot buckling was seen at the end of the specimens (Fig. 5 (a)). The outward buckling of steel tube, to a great extent, was the result of the expansion of crushed concrete core (Fig. 5 (b)), which strongly supported the view that under external loads, the steel tube and concrete core could work well together, and the presence of the concrete core in turn efficiently prevented the occurrence of inward buckling.
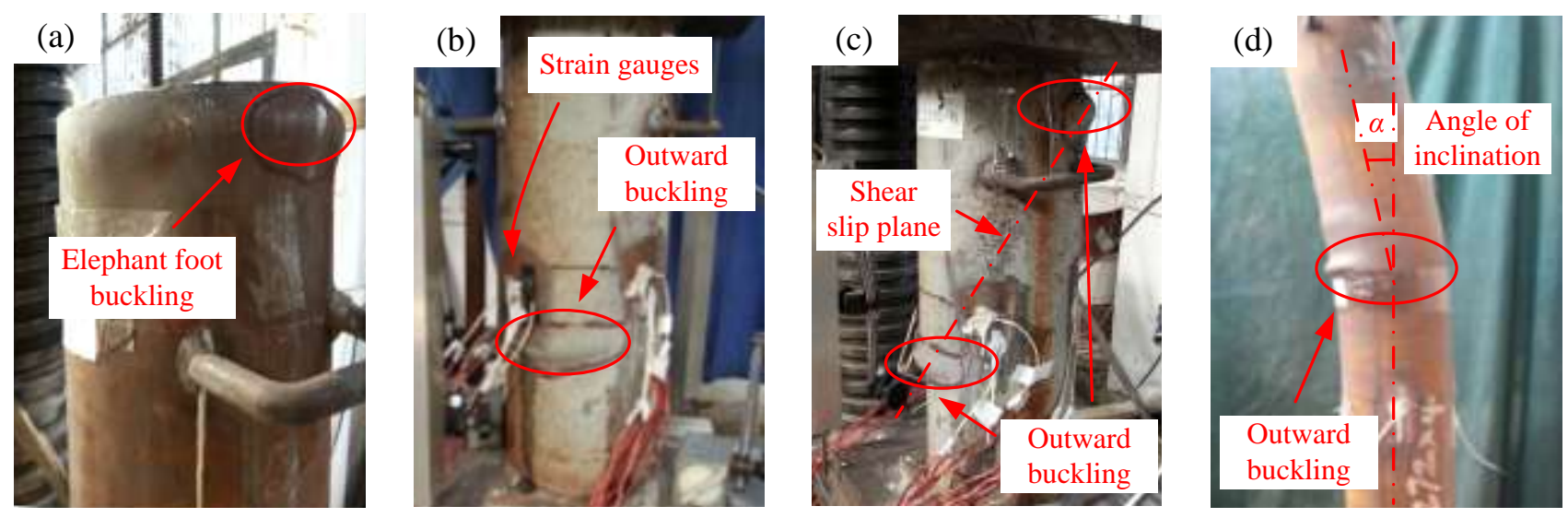

Fig. 5 Experimental observations and typical failure modes. 
However, although the introduction of HSS concrete improved the compression performance obviously, it did not change the failure mode. Two failure modes, i.e. the shear failure and flexural failure, mainly depending on the length-to-diameter ratio $(L / D)$, were observed in this study, as shown in Fig. 5 (c) and (d), respectively. For the shear failure mode, which was only found in the case of $L / D=3$, where obvious diagonal outward buckling was found at opposite faces of the steel tube, and one dominant shear crack could be clearly seen in the concrete core after removing the steel tube. A sudden drop in load bearing capacity was observed when the diagonal shear slip plane formed. For flexural failure mode, it was commonly found in the cases of $L / D=5,8,10$, and 12 . The outward bucklings initially formed at one side of the steel tube, and with further loading, the specimen would deviate from its vertical position and incline in the direction of buckling subsequently. In general, this type of failure mode is more ductile when compared with the shear failure mode, hence, the loading bearing capacity of these specimens tended to drop moderately.

\subsection{Load-deformation curves}

For better understanding of the uniaxial compression performance of HSS-CFST columns, Fig. 6 and Fig. 7 illustrate the load-axial displacement and load-strain curves of the specimens with different self-stress levels, concrete strengths, tube thicknesses, and length-to-diameter ratios respectively, from which the following observations can be made:

(1) In general, similar to the conventional CFSTs, the typical load-axial displacement curves of the HSS-CFSTs can be also divided into three stages, i.e. the elastic stage, elastoplastic stage, and post-peak stage. However, it is interesting to find that the elastic stage of the HSS-CFSTs can reach almost $90 \%$ of the ultimate bearing capacity, which is obviously higher than that (approximate 70\%) of conventional CFSTs. At the elastic stage, the hoop and axial strains of steel tubes both increased linearly, and the ratio $\varepsilon_{\theta} / \varepsilon_{z}$ was around 0.23 to 0.27 , which was close to the tested Poisson's ratio $\left(v_{s} \approx 0.27\right)$. Further loading, the strain in either direction began to increase nonlinearly, and at last the axial strain $\varepsilon_{z}$ was as high as 3000 to $3500 \mu \varepsilon$ when the ultimate bearing capacity was reached, which was far beyond the yielding strain $\left(f_{y} \approx 1850 \mu \varepsilon\right)$.

(2) In terms of the ultimate bearing capacity and post-peak ductility, the specimen with a higher self-stress always exhibited a better uniaxial compression performance (Fig. 6 (a)). This phenomenon is mainly attributed to the improvements in mechanical properties of concrete core. To be more specific, due to the presence of self-stress, the inner concrete core is always in a triaxial compression state, which can effectively inhibit the crack propagation, and greatly increase the compressive strength of concrete. The load-strain relationships shown in Fig. 7 (a), where the strains in steel tube are generally bigger for the specimens with a higher self-stress, also support this observation. 

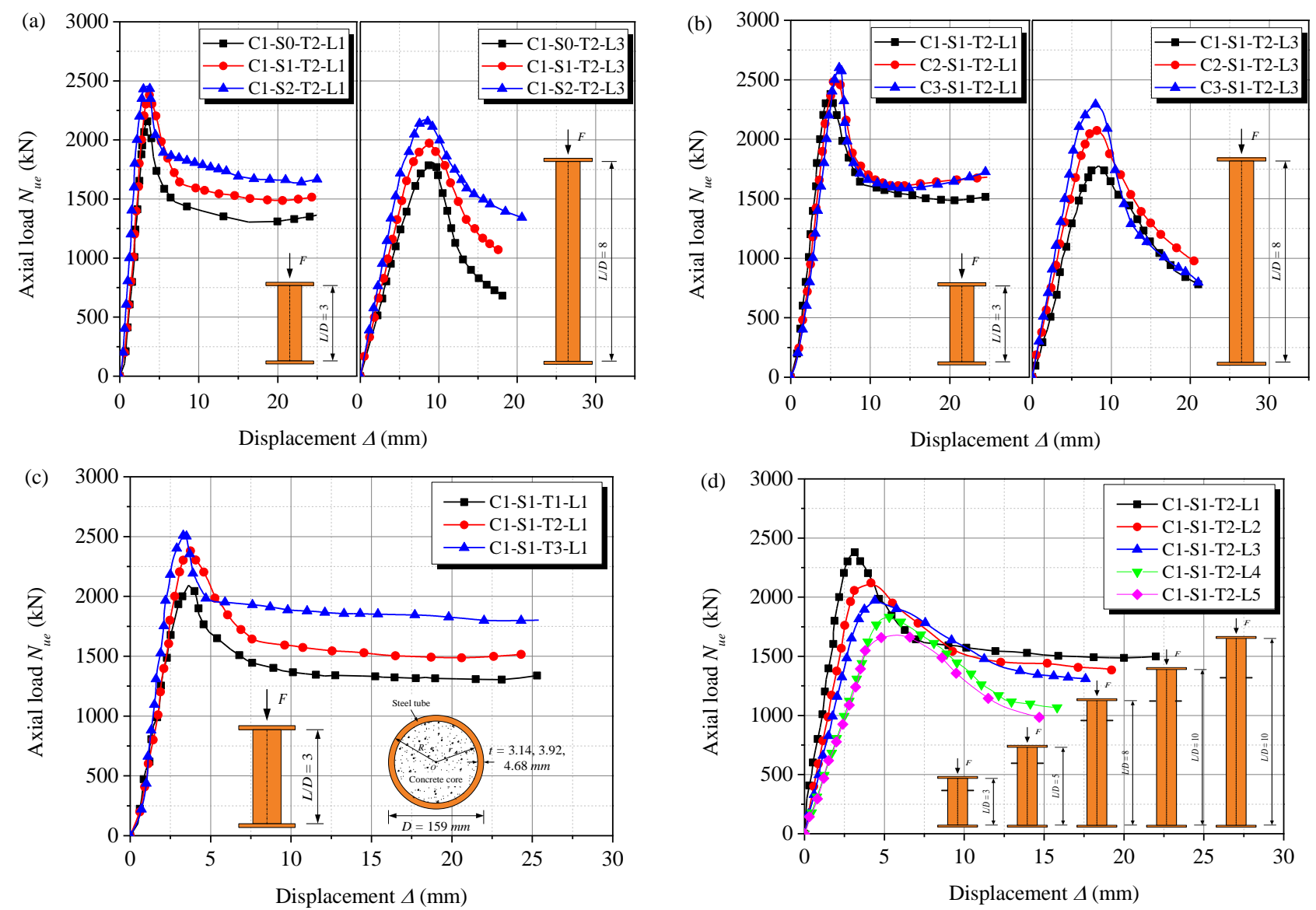

Fig. 6 The load-displacement relationships of HSS-CFST. Influences of (a) self-stress level; (b) concrete strength; (c) tube thickness; (d) length-to-diameter ratio.

(3) The concrete strength had a positive correlation with the specimen's ultimate bearing capacity, while showed limited relation to the post-peak behavior, as illustrated in Fig. 6 (b). It can be explained by the fact that as the concrete strength increases, apart from the advantageous influences on improving the bearing capacity, the concrete becomes brittler. Hence, at the post-peak stage, the strain of steel tube filled with the concrete having a higher strength experienced a greater reduction (Fig. 7 (b)).

(4) As shown in Fig. 6 (c), a thicker steel tube always results in an increased load bearing capacity and better dissipation of energy. This observation is quite different from that of conventional CFSTs. According to [20], the outer steel tube will dilate faster than inner concrete when subjected to axial load, which will greatly reduce the confining pressure and thus the bearing capacity of the specimens. However, with the help of self-stress, a reliable mutual confinement can be ensured (Fig. 7 (c)). Hence, the premature concrete crush can be delayed, and a better uniaxial compression performance is therefore obtained.

(5) From Fig. 6 (d), it is clearly that for the specimens with a larger length-to-diameter ratio, a smaller bearing capacity is expected. Because of the P- $\Delta$ effect, the relationship between the axial load and mid-length moment is no longer linear when the length of specimens is increased, and the unwanted secondary moment generated by the lateral deflection will exert an adverse effect on the bearing capacity of specimens. As the location of buckling is not necessarily at mid-height for a long specimen, the strains at mid-height may decrease (Fig. 7 (d)) after strain concentration occurs at other locations. 

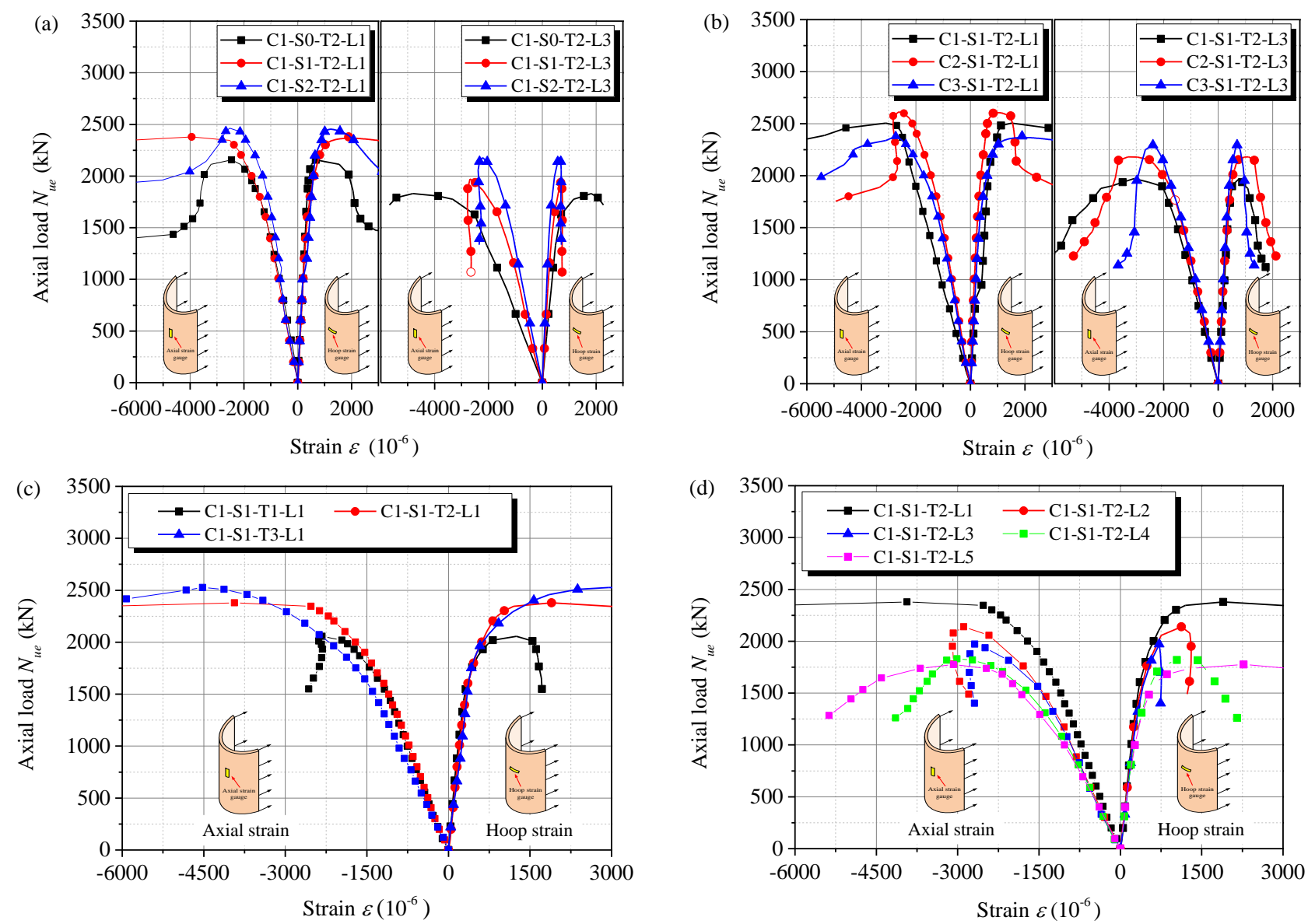

Fig. 7 The load-strain relationships of HSS-CFST. Influences of (a) self-stress level; (b) concrete strength; (c) confinement factor; (d) length-to-diameter ratio.

\section{Numerical simulation}

In order to simulate the uniaxial compressive behavior of HSS-CFSTs, the three main components, i.e. the outer steel tube, the infilled concrete core, and the interfacial properties, need to be accurately modeled. This process requires well defiend and properly chosen constitutive relations, element types, mesh sizes, boundary and loading conditions.

\subsection{Constitutive models}

\subsubsection{Carbon steel}

To date, many elaborate constitutive relations for steel have already been proposed [21]. For simplicity, a bilinear stress-strain curve developed by the elastic-plastic model in ABAQUS [22], as shown in Fig. 8 (a), was used in this work. The elastic modulus $E_{s}$, Poisson's ratio $\mu_{s}$, and yield strength $f_{y}$ for the carbon steel were from the test results listed in Table 2, and a hardening modulus of $0.01 E_{s}$ was adopted after yielding.

\subsubsection{Concrete core}

The concrete damaged plastic (CDP) model provided by the material library was employed for the concrete core, and the stress-strain model (Eq. 5) provided by GB 50010-2010 [23] was used to simulate its plastic behaviour (Fig. $8(b))$, 


$$
\sigma= \begin{cases}f_{c}\left[\alpha_{a}\left(\varepsilon / \varepsilon_{c}\right)+\left(3-2 \alpha_{a}\right)\left(\varepsilon / \varepsilon_{c}\right)^{2}+\left(\alpha_{a}-2\right)\left(\varepsilon / \varepsilon_{c}\right)^{3}\right] & \varepsilon \leq \varepsilon_{c} \\ f_{c} \frac{\varepsilon / \varepsilon_{c}}{\alpha_{d}\left(\varepsilon / \varepsilon_{c}-1\right)^{2}+\varepsilon / \varepsilon_{c}} & \varepsilon \geq \varepsilon_{c}\end{cases}
$$

where $\varepsilon_{c}$ is the strain at peak compressive strength, and $\alpha_{a}, \alpha_{d}$ are the parameters that control the shape of ascending branch and descending branch, respectively.

The elastic modulus $E_{c}$ and Poisson's ratio $v_{c}$ were given as $E_{c}=4700 \cdot f_{c}^{0.5}$ and $v_{c}=0.2$ respectively, according to the recommendations in ACI Committee 318 [24]. Dilation angle, eccentricity, biaxial/uniaxial ratio and $K$ were respectively set as 40, 0.1, 1.225 and 0.667 [25,26]. Moreover, a small value for the viscosity parameter, 0.0005 , was given to improve the convergence rate.

\subsubsection{Self-stress}

The above models have already been well validated to simulate conventional CFST under various loading histories. For HSS-CFST, the effect of self-stress must be taken into consideration in the simulation.

Inspired by the fact that a material expands under elevated temperature, this study attempted to prestress the concrete by means of increasing temperature. During the simulation, the expansion coefficient of the core concrete was $10^{-5} /{ }^{\circ} \mathrm{C}$, and that of the steel tube was assumed to be zero. The difference in the thermal expansion can simulate the situation that the expansive concrete is confined by the steel tube when temperature increases. A preliminary simulation showed that an approximate linear relation between the radial self-stress and increased temperature was observed, and the numerical predictions for the case of this paper are illustrated in Fig. 8 (c).

(a)

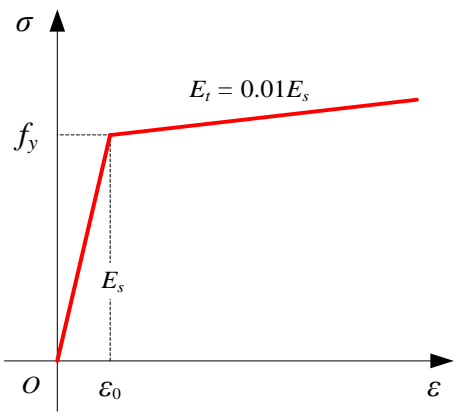

(b)

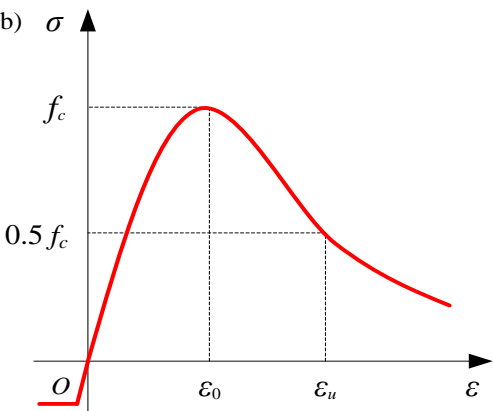

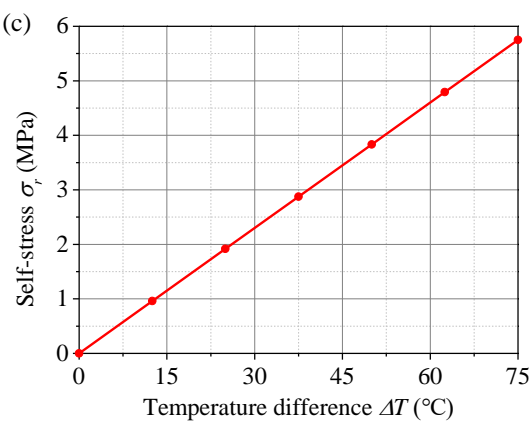

Fig. 8 The constitutive models of (a) steel and (b) concrete, and (c) the relation between the self-stress and temperature difference.

\subsection{Finite element mesh and boundary conditions}

Literature review has proved that the solid element available in ABAQUS is capable of simulating mechanical response of concrete core and steel tube with sufficient accuracy [27-29]. Hence, in this study, the three-dimensional eight-node linear brick and reduced integration with hourglass control solid element (C3D8R) was employed, as shown in Fig. 9 (a). Considering the fact that the contact surfaces between these two materials allow separation from each other rather than penetration, the interaction was defined as a surface-to-surface that contains a hard contact model in the normal direction and a Mohr-Coulomb friction model in the tangential direction (Fig. 9 (b)). As defined, the tangential friction between the contact surfaces is maintained as long as the faces remain in contact, and the friction coefficient is taken as $0.6[1,28]$.

In the simulations, the columns were fixed with a pinned at the bottom end, and subjected to compression form the top by controlling downwards displacement. Moreover, to accelerate the convergence of calculation, two rigid 
loading plates were tied to both ends of model, as illustrated in Fig. 9 (a). Finally, for the purpose of achieving reliable results with less computational time, five numerical models with different element sizes were compared to assess the effect of mesh sensitivity (Fig. 9 (c)), from which, the model with a mesh size of $25 \mathrm{~mm}$ was regarded as most appropriate for this study.

(a) Core concrete

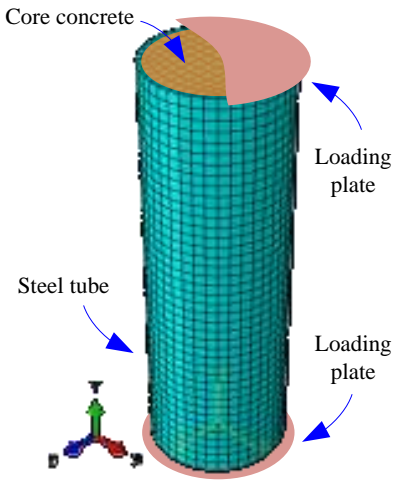

(b)

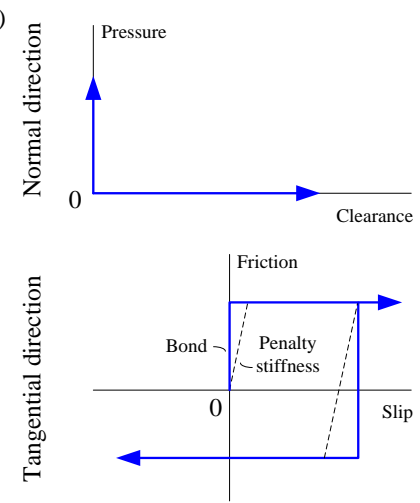

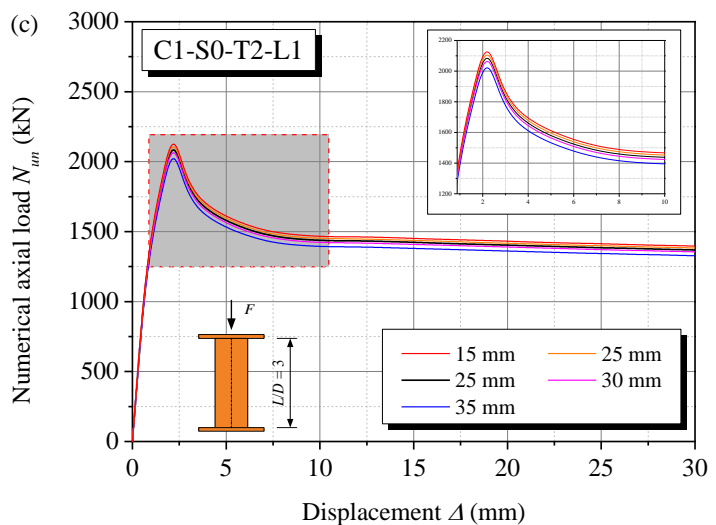

Fig. 9 Numerical simulation. (a) finite element model, (b) interaction property of contact surfaces, (c) mesh sensitivity study.

\subsection{Model verification}

The results of the numerical simulations were illustrated in Fig. 10, where comparisons were made with the experimental results to verify the models.

The failure modes shown in Fig. 10 (a) are similar to those from the test results in Fig. 5. The predictions of load-displacement relations of the HSS-CFST with different length-to-diameter ratios are plotted in Fig. 10 (b). In general, a satisfactory agreement is found when compared with the test results shown in Fig. 6 (d).

The above numerical simulations, especially the verification of ultimate bearing capacity of the 51 specimens (17 groups) shown in Fig. 10 (c), solidly suggested that the finite element model established in this study was able to simulate the compressive behavior of HSS-CFST accurately, and the approach adopted to pre-stress the concrete core worked satisfactorily. The effect of self-stress on the ultimate bearing capacity was further analyzed, and the predictions for the HSS-specimens having different length-to-diameter ratios were plotted in Fig. 10 (d).

(a)

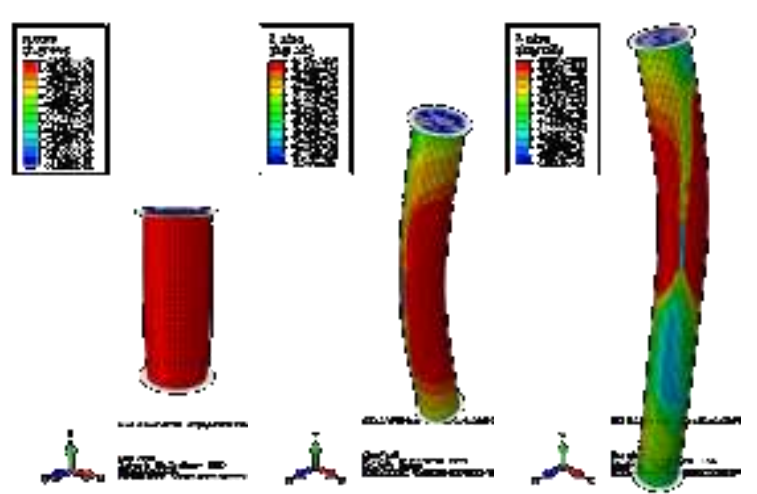

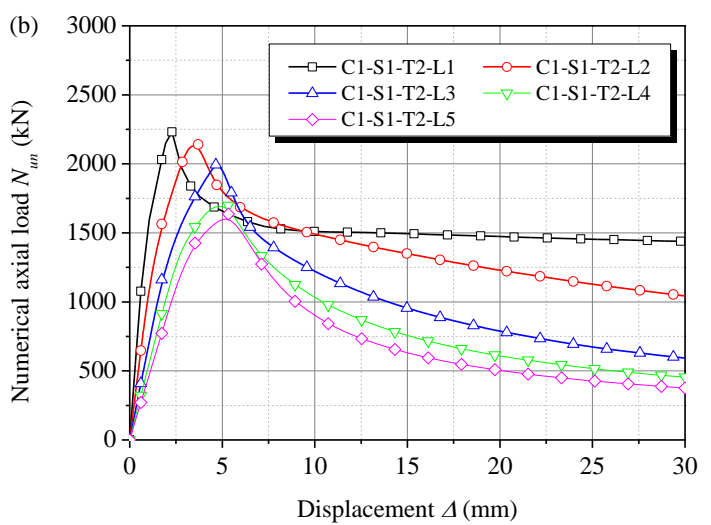



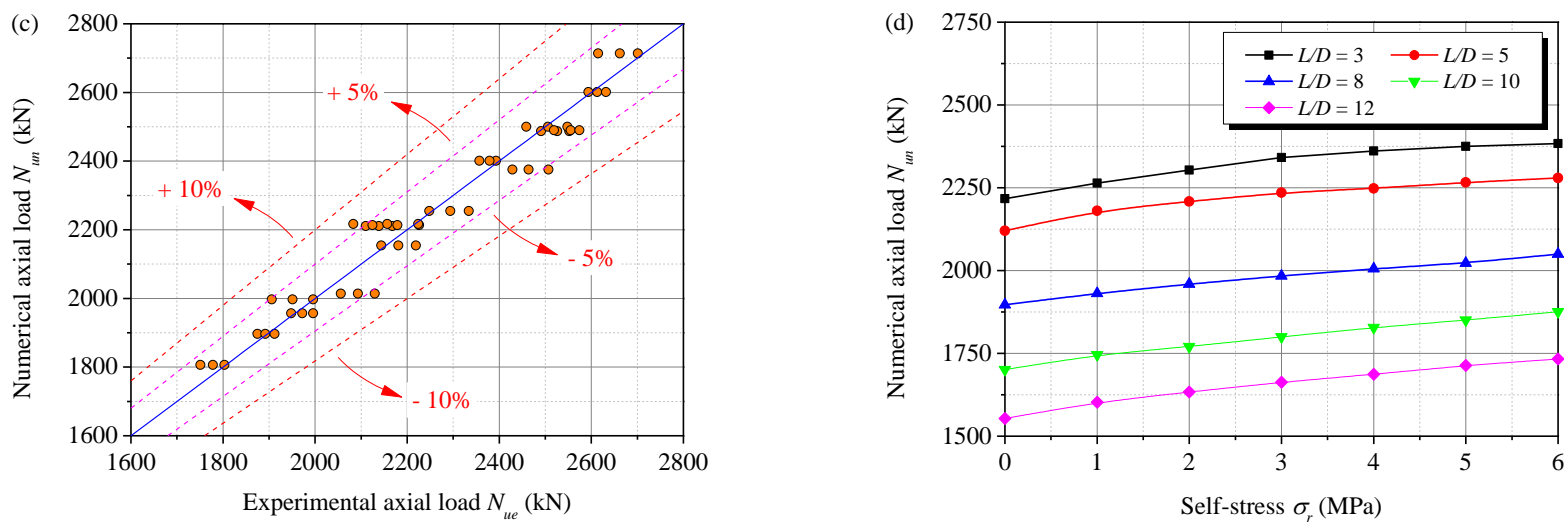

Fig. 10 Numerical results. (a) failure modes, (b) the complete axial load-displacement curves of HSS-CFSTs with different length-todiameter ratios, (c) comparison between the predicted and experimental results of ultimate bearing capacity, (d) effect of self-stress.

\section{Calculation of ultimate bearing capacity}

In this Section, prior to providing the formulas to calculate the ultimate bearing capacity of HSS-CFST columns, parametric studies on the effect of self-stress, concrete strength, tube thickness and length-to-diameter ratio are performed.

\subsection{Parametric analysis}

As shown in Fig. 11 (a), the influence of self-stress is analyzed, considering three nominal levels, i.e. 0,3 , and 5 $\mathrm{MPa}$. It can be seen that an increase in self-stress always leads to an improvement in ultimate bearing capacity. More specifically, in comparison with the non-stressed specimen C1-S0-T2-L1(3), the specimens having self-stress of 3 and $5 \mathrm{MPa}$ can improve the ultimate bearing capacity by $6.0 \%$ and $12.4 \%$, correspondingly. A similar trend can be observed for the specimens with different concrete strengths (Fig. 11 (b)), and the improvements can be $5.3 \%$ and $9.8 \%$ respectively when comparing the specimens C2-S1-T2-L1(3) and C3-S1-T2-L1(3) with C1-S1-T2-L1(3).

Under otherwise constant conditions, the increase of steel tube thickness has a positive effect on enhancing the ultimate bearing capacity (Fig. 11 (c)). Compared with the specimen C1-S1-T1-L1 $(t=3.14 \mathrm{~mm})$, an increase of $15.7 \%$ and $20.2 \%$ can be obtained for the specimens C1-S1-T2-L1 $(t=3.92 \mathrm{~mm})$ and C1-S1-T3-L1 $(t=4.68 \mathrm{~mm})$, respectively. Whereas, as aforementioned that the length-to-diameter ratio exerted an adverse effect on the bearing capacity of specimens, the reductions are $10.1 \%, 17.1 \%, 18.0 \%$ and $25.3 \%$, when the ratio $L / D$ ranges from 3 to 5 ,

8, 10, and 12 (Fig. 11 (d)).

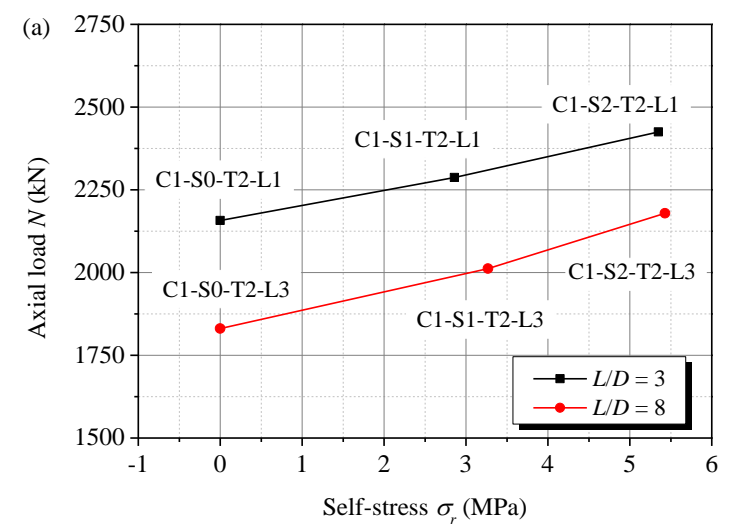

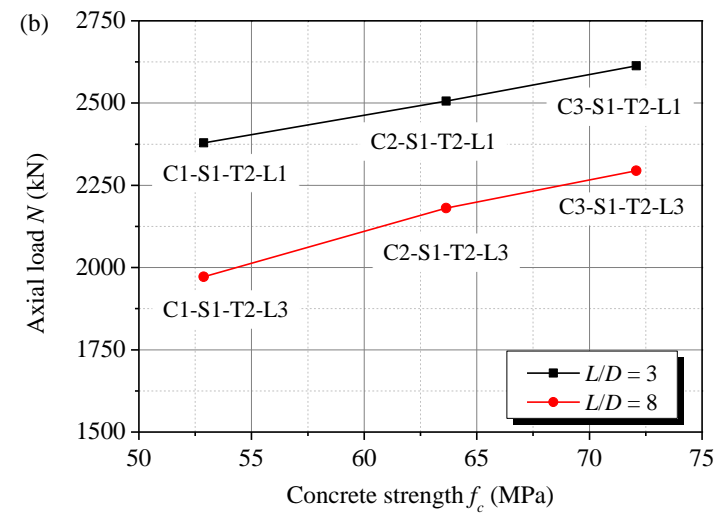



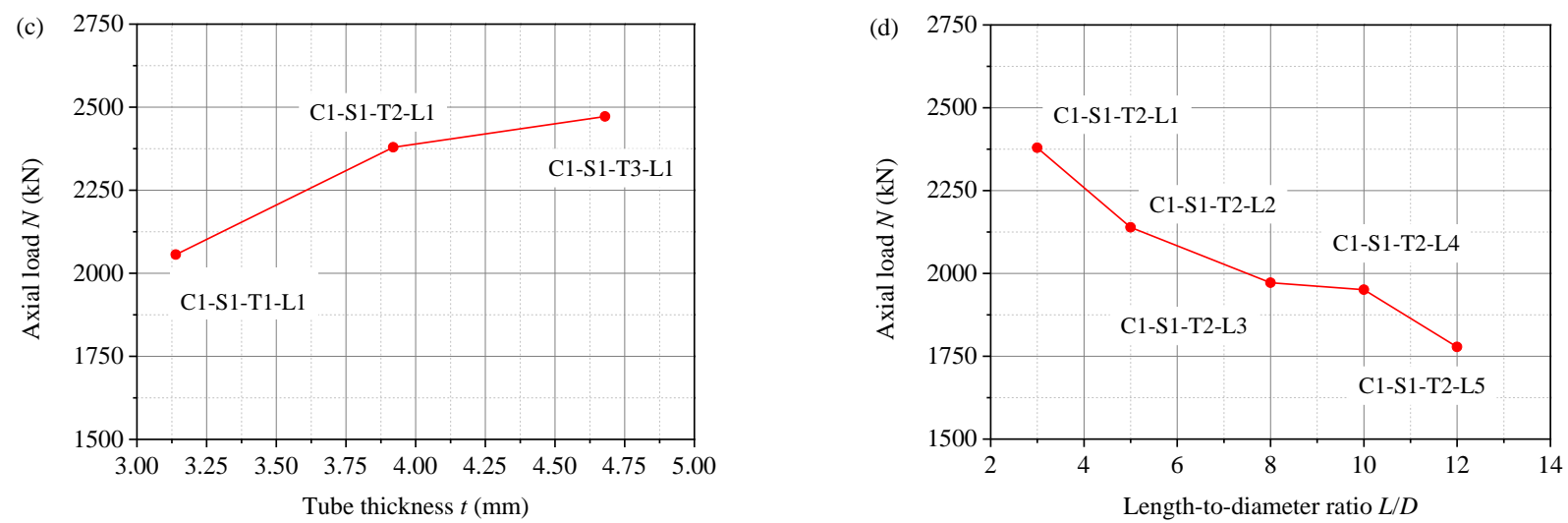

Fig. 11. The relationship between ultimate bearing capacity and (a) self-stress level; (b) concrete strength; (c) tube thickness; (d) length-to-diameter ratio.

\subsection{Existing codes and specifications}

Currently, design codes and specifactions have already provided many classical formulas for calculating the ultimate bearing capacity of conventional CFST columns subjected to uniaxial compression, among which the followings are used widely:

(1) AIJ model [30]

For a specimen with a length-to-diameter ratio $L / D \leq 4$, the ultimate bearing capacity can be calculated as

$N_{u 1}=(1+\omega) A_{s} f_{y}+0.85 A_{c} f_{c}^{\prime}$

and when $4<L / D \leq 12$,

$N_{u 2}=N_{u 1}-\frac{\left(N_{u 1}-N_{u 3}\right)}{8}\left(\frac{K L}{D}-4\right)$

where $N_{u 1}, N_{u 2}, N_{u 3}$ are the ultimate bearing capacity of a CFST column with different length-to-diameter ratios; $A_{s}$, $A_{c}$ are the cross sectional areas of the steel tube and core concrete, respectively; $f_{y}, f_{c}^{\prime}$ are the yielding strength and cylinder compressive strength of corresponding materials; $K$ is the effective length factor, and $K=1$ for the case of hinge joint; $\omega$ is a compensation factor, and for a circular CFST column, $\omega=0.27$.

(2) EC 4 model [31]

The ultimate bearing capacity for a column stub is calculated by adding the resistance of constituent steel and concrete materials as follows:

$N_{0}=A_{s} f_{y}+A_{s} f_{c}$

To account for the effect of increasing length-to-diameter ratio, a reduction factor $\varphi$ is subsequently introduced,

$N_{u}=\varphi N_{0}$

$\varphi= \begin{cases}1 & \lambda \leq 0.2 \\ 1 /\left(\varphi_{0}+\sqrt{\varphi_{0}^{2}-\lambda^{2}}\right) & \lambda>0.2\end{cases}$

$\varphi_{0}=0.5\left[1+0.21(\lambda-0.2)+\lambda^{2}\right]$

$\lambda_{c r}=\sqrt{N_{0} / N_{c r}}$

where $\lambda_{c r}$ represents the relative slenderness; $N_{c r}=\pi^{2}\left(E I_{e f f}\right) /(K L)^{2}$ is the Euler's critical load, and $E I_{e f f}$ is the effective stiffness of composite section. 
(3) AISC 360 model [32]

This model introduces a factor of 0.85 to account for the reduction of concrete strength,

$N_{0}=A_{s} f_{y}+0.85 A_{c} f_{c}^{\prime}$

and the reduction factor $\varphi$ for the effect of length-to-diameter ratio is defined differently as,

$\varphi= \begin{cases}0.658^{\lambda_{n}^{2}} & \lambda_{n}^{2} \leq 1.5 \\ 0.877 / \lambda_{n}^{2} & \lambda_{n}^{2}>1.5\end{cases}$

$\lambda_{n}=\frac{K L}{\pi r} \sqrt{\frac{F_{m y}}{E_{m}}}$

where $\lambda_{n}$ is the regular slenderness of CFST column; $r$ is the radius of gyration; $F_{\mathrm{my}}$ represents its equivalent yielding strength, and $E_{\mathrm{m}}$ represents the equivalent elastic modulus. Generally, $F_{\mathrm{my}}=f_{y}+0.85 f_{c}^{\prime}\left(A_{c} / A_{s}\right), E_{\mathrm{m}}=E_{s}+$ $0.4 E_{c}\left(A_{c} / A_{s}\right)$.

(4) GB 50936 models [33]

Two completely different formulas, repectively proposed by Zhong [34] and Cai [35], are provided in code GB 50936-2014, as follows.

1. Zhong's model

This model regards the steel tube and concrete core as an entity, and takes the contribution of confinement effect into consideration,

$N_{0}=A_{s c} f_{s c}$

where $A_{s c}, f_{s c}$ are the gross areas and compressive strength of CFST column. They are define as: $A_{s c}=A_{s}+A_{c}, f_{s c}=$ $\left(1.212+B \xi+C \xi^{2}\right) f_{c}$, where the parameters $B$ and $C$ are given as: $B=0.176 f_{y} / 235+0.974, C=-0.104 f_{c} / 20+$ 0.031 .

For a slender column, the reduction factor $\varphi$ is defined as

$\varphi=\frac{1}{2 \lambda_{n}^{2}}\left[\lambda_{n}^{2}+\left(1+0.25 \lambda_{n}\right)-\sqrt{\left(\lambda_{n}^{2}+\left(1+0.25 \lambda_{n}\right)\right)^{2}-4 \lambda_{n}^{2}}\right]$

$\lambda_{n}=\frac{K L}{\pi r} \sqrt{\frac{f_{s c}}{E_{s c}}} \approx 0.01 \frac{K L}{r}\left(0.001 f_{y}+0.781\right)$

where $E_{s c}$ represents the elastic modulus of CFST column.

2. Cai's model

This model is based on the limit equilibrium theory, and incorporates the influences of concrete strength and the benefits of confinement,

$N_{0}=0.9 A_{c} f_{c}(1+\alpha \xi)$

In the case of $\xi \leq 1 /(\alpha-1)^{2}$, the reduction factor $\varphi$ is defined as

$\varphi= \begin{cases}1 & K L / D \leq 4 \\ 1-0.0226(K L / D-4) & 4<K L / D \leq 30\end{cases}$

where $\alpha$ is a coefficient associated to concrete strength, and $\alpha=1.8$ when the nominal compressive strength is between $50 \mathrm{MPa}$ and $80 \mathrm{MPa}$.

Table 4 
Comparisons between the test results and the predictions of codes.

\begin{tabular}{|c|c|c|c|c|c|c|c|c|c|c|c|c|}
\hline \multirow{2}{*}{ No. } & \multirow{2}{*}{ Specimen } & \multirow{2}{*}{$N_{u e}$} & \multicolumn{2}{|c|}{ AIJ } & \multicolumn{2}{|c|}{ EC 4} & \multicolumn{2}{|c|}{ AISC 360-05 } & \multicolumn{4}{|c|}{ GB 50936-2014 } \\
\hline & & & $N_{u-\mathrm{AIJ}}$ & $N_{u-\mathrm{AIJ}} / N_{u e}$ & $N_{u \text {-EC }}$ & $N_{u-\mathrm{EC}} / N_{u e}$ & $N_{u \text {-AISC }}$ & $N_{u \text {-AISC }} / N_{u e}$ & $N_{u-\mathrm{GB} 1}$ & $N_{u-\mathrm{GB} 1} / N_{u e}$ & $N_{u-\mathrm{GB} 2}$ & $N_{u-\mathrm{GB} 2} / N_{u e}$ \\
\hline 1 & C1-S1-T1-L1 & 2093 & 1663 & 0.79 & 1694 & 0.81 & 1508 & 0.72 & 1748 & 0.84 & 1732 & 0.83 \\
\hline 2 & C1-S1-T2-L1 & 2379 & 1859 & 0.78 & 1840 & 0.77 & 1657 & 0.70 & 1927 & 0.81 & 1990 & 0.84 \\
\hline 3 & C1-S1-T3-L1 & 2526 & 1948 & 0.77 & 1903 & 0.75 & 1723 & 0.68 & 2004 & 0.79 & 2112 & 0.84 \\
\hline 4 & C1-S1-T2-L2 & 2139 & 1615 & 0.76 & 1816 & 0.85 & 1635 & 0.76 & 1895 & 0.89 & 1945 & 0.91 \\
\hline 5 & C1-S1-T2-L3 & 1972 & 1577 & 0.80 & 1745 & 0.88 & 1583 & 0.80 & 1844 & 0.94 & 1810 & 0.92 \\
\hline 6 & C1-S1-T2-L4 & 1951 & 1523 & 0.78 & 1688 & 0.87 & 1537 & 0.79 & 1808 & 0.93 & 1720 & 0.88 \\
\hline 7 & C1-S1-T2-L5 & 1778 & 1475 & 0.83 & 1619 & 0.91 & 1482 & 0.83 & 1770 & 1.00 & 1630 & 0.92 \\
\hline 8 & C1-S2-T2-L1 & 2464 & 1865 & 0.76 & 1847 & 0.75 & 1663 & 0.67 & 1935 & 0.79 & 1996 & 0.81 \\
\hline 9 & C1-S2-T2-L3 & 2179 & 1581 & 0.73 & 1751 & 0.80 & 1589 & 0.73 & 1851 & 0.85 & 1816 & 0.83 \\
\hline 10 & C2-S1-T2-L1 & 2506 & 2056 & 0.82 & 2072 & 0.83 & 1851 & 0.74 & 2162 & 0.86 & 2164 & 0.86 \\
\hline 11 & C2-S1-T2-L3 & 2181 & 1728 & 0.79 & 1953 & 0.90 & 1760 & 0.81 & 2069 & 0.95 & 1968 & 0.90 \\
\hline 12 & C2-S2-T2-L1 & 2555 & 2077 & 0.81 & 2097 & 0.82 & 1872 & 0.73 & 2187 & 0.86 & 2183 & 0.85 \\
\hline 13 & C3-S1-T2-L1 & 2613 & 2210 & 0.85 & 2254 & 0.86 & 2003 & 0.77 & 2346 & 0.90 & 2300 & 0.88 \\
\hline 14 & C3-S1-T2-L3 & 2294 & 1855 & 0.81 & 2114 & 0.92 & 1897 & 0.83 & 2245 & 0.98 & 2092 & 0.91 \\
\hline 15 & C3-S2-T2-L1 & 2662 & 2218 & 0.83 & 2263 & 0.85 & 2011 & 0.76 & 2356 & 0.89 & 2307 & 0.87 \\
\hline 16 & C1-S0-T2-L1 & 2157 & 1945 & 0.90 & 1942 & 0.90 & 1742 & 0.81 & 1965 & 0.91 & 2129 & 0.99 \\
\hline 17 & C1-S0-T2-L3 & 1829 & 1640 & 0.90 & 1840 & 1.01 & 1661 & 0.91 & 1880 & 1.03 & 1936 & 1.06 \\
\hline \multicolumn{2}{|c|}{ Remarks: } & $\mathrm{AVG}$ & & 0.81 & & 0.85 & & 0.77 & & 0.89 & & 0.89 \\
\hline & & SD & & 0.05 & & 0.07 & & 0.06 & & 0.07 & & 0.05 \\
\hline
\end{tabular}

The comparisons between the test results and predictions of above models are summarized in Table 4, from which it can be clearly seen that all of these formulas underestimate the ultimate bearing capacity of HSS-CFST columns, especially from the AIJ, EC 4 and AISC 360 models. One of the main reasons to account for this is that in these codes, the confinement effect provided by the steel tube is not or not fully considered. As to the two models from GB 50936-2014, whose accuracies in calculating the ultimate bearing capacity of conventional CFST columns have already been well validated by extensive experimental results [36-41], their conservativeness in this study therefore are assumed to be the neglect of contributions caused by the self-stress.

\subsection{Proposed model}

According to the analyses mentioned above, the beneficial effects of self-stress should be appropriately included in the formula for evaluating the ultimate bearing capacity. Hence, a modified model is proposed in this section, inspired by the work done by Cai,

$N_{0}=0.9 A_{c} f_{c}(1+\alpha \xi+\beta)$

where $\beta$ is an improvement factor. Based on the least-squares analysis, it can be found that this factor shows a quadratic relationship with the self-stress level, as shown in Fig. 12,

$\beta=-19.2 \eta^{2}+7.5 \eta$

where $\eta$ represents the relative self-stress, which is the ratio of self-stress and concrete compressive strength, i.e.,

$\eta=\sigma_{r} / f_{c}$

The ultimate strengths of the 17 HSS-CFST columns, including 8 slender specimens, are calculated using Eqs. (20) (23). The predictions are compared to the test results, which is illustrated in the left part of Fig. 13. It is 
observed that the proposed model provides a fairly good estimate of the ultimate bearing capacity for the short columns, whereas the results of slender specimens show an obvious deviation. This is mainly due to the inapplicability of the reduction factor $\varphi$, which should include the effect of self-stress as well. Considering this, a factor $\gamma$ to reflect this influence on the reduction of the ultimate bearing capacity of a slender column is therefore introduced,

$$
\varphi^{*}= \begin{cases}1 & K L / D \leq 4 \\ 1-0.0226 \gamma(K L / D-4) & 4<K L / D \leq 30\end{cases}
$$

Likewise, this factor is also defined on the basis of a least-squares analysis, and is thought to be linear with the relative self-stress, that is,

$\gamma=1+11.5 \eta$

The ultimate bearing capacities of all the HSS-CFST columns are calculated with Eqs. (21) (25), which are plotted in the right part of Fig. 13, from which it can be clearly seen that the predictions using the modified formulas agree well with the test results, with an average ratio 0.99 and a standard deviation 0.02 .

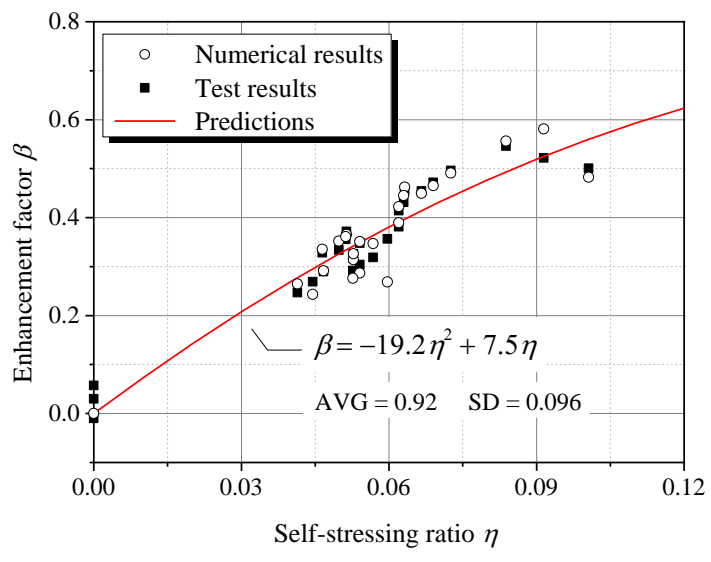

Fig. 12. Typical load-displacement curve for the specimens.

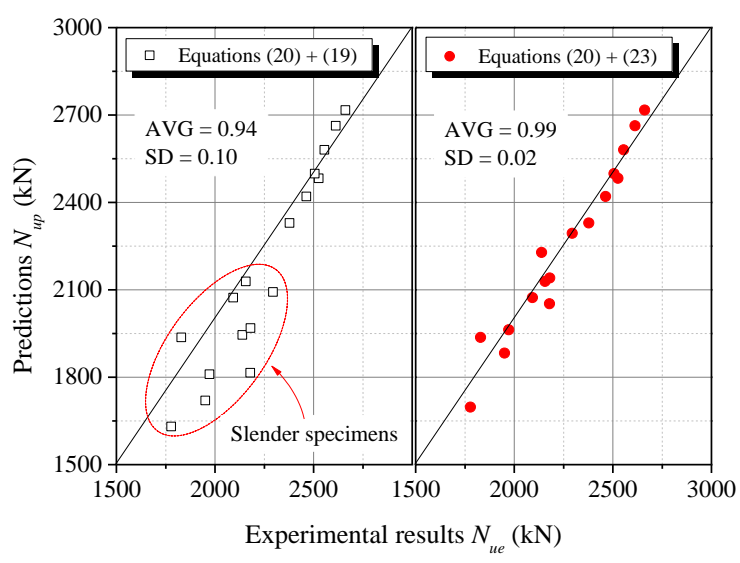

Fig. 13. Typical load-displacement curve for the specimens.

\section{Conclusions}

Based on the experimental and analytical investigations on 17 groups of HSS-CFST columns described above, the following conclusions can be drawn:

(1) Due to the positive effect of self-stress, HSS-CFST columns generally exhibited better uniaxial compression performance. In comparison with conventional CFST specimens, an increase of $12.4 \%$ in ultimate bearing capacity could be achieved for a HSS-CFST specimen having self-stress of $5 \mathrm{MPa}$, and this improvement would become more pronounced as the length-to-diameter ratio increases.

(2) Increasing the concrete strength had an advantageous influence on the bearing capacity of HSS-CFST specimen, but little benefit on the post-peak ductility was found, indicating that the favorable contribution at post-peak stage was counteracted by the higher brittleness of core concrete. Moreover, a thicker steel tube always led to a preferable compression performance because of the stronger confinement on the concrete core, while an increase of length-to-diameter ratio showed an opposite effect owing to the bigger P- $\Delta$ effect.

(3) Finite element modelling of HSS-CFST columns under uniaxial compression was performed, in which the self-stress was simulated. Close agreement between the experimental and numerical results was obtained.

(4) Based on the current code, an empirical formula considering the effect of self-stress was proposed to 
calculate the ultimate bearing capacity of HSS-CFST columns with reasonable accuracy.

\section{References}

[1] Han LH, He SH, Liao FY. Performance and calculations of concrete filled steel tubes (CFST) under axial tension. J Constr Steel Res 2011; 67(11): 1699-1709.

[2] Shams M, Saadeghvaziri MA. State of the art of concrete-filled steel tubular columns. ACI Struct J 1997; 94(5): $558-571$.

[3] Moon J, Kim JJ, Lee TH, Lee HE. Prediction of axial load capacity of stub circular concrete-filled steel tube using fuzzy logic. J Constr Steel Res 2014; 101: 184-191.

[4] Zhu MC, Liu JX, Wang QX, Feng XF. Experimental research on square steel tubular columns filled with steel-reinforced self-consolidating high-strength concrete under axial load. Eng Struct 2010; 32(8): 2278-2286.

[5] Rangan BV, Joyce M. Strength of eccentrically loaded slender steel tubular columns filled with high-strength concrete. ACI Struct J 1992; 89(6): 676-681.

[6] Liang QQ. Strength and ductility of high strength concrete-filled steel tubular beam-columns. J Constr Steel Res 2009; 65(3): 687-698.

[7] Varma AH, Ricles JM, Sause R, Lu LW. Experimental behavior of high strength square concrete-filled steel tube beam-columns. J Struct Eng, ASCE 2002; 128(3): 309-318.

[8] Liu D, Gho WM, Yuan J. Ultimate capacity of high-strength rectangular concrete-filled steel hollow section stub columns. J Constr Steel Res 2003; 59: 1499-1515.

[9] Liu D. Tests on high-strength rectangular concrete-filled steel hollow section stub columns. J Constr Steel Res 2005; 61: 902-911.

[10] Yu M, Zha XX, Ye JQ, Li YT. A unified formulation for circle and polygon concrete-filled steel tube columns under axial compression. Eng Struct, 2013,49:1-10.

[11] Yu M, Zha XX, Ye JQ, She CY. A unified formulation for hollow and solid concrete-filled steel tube columns under axial compression. Eng Struct, 2010, 32(4):1046-1053.

[12] Xue JQ, Briseghella B, Chen BC. Effects of debonding on circular CFST stub columns. J Constr Steel Res 2012; 69(1): 64-76.

[13] Idorn GM. Expansive mechanisms in concrete. Cement Concrete Res, 1992, 22(6): 1039-1046.

[14] Han J, Jia D, Yan P. Understanding the shrinkage compensating ability of type K expansive agent in concrete. Constr Build Mater 2016; 116: 36-44.

[15] Liu F, Shen SL, Hou DW, Arulrajah A, Horpibulsuk, S. Enhancing behavior of large volume underground concrete structure using expansive agents. Constr Build Mater 2016; 114: 49-55.

[16] Huang CK, Liu Y. Expansive performance of self-stressing and self-compacting concrete confined with steel tube. J Wuhan Univ Technol 2007; 22(2): 341-345.

[17] Chang X, Huang CK, Jiang DC, Song YC. Push-out test of pre-stressing concrete filled circular steel tube columns by means of expansive cement. Constr Build Mater 2009; 23(1): 491-497.

[18] Chang X, Lin HX, Huang CK. Experimental study on shear resistance of self-stressing concrete filled circular steel tubes. J Constr Steel Res 2009; 65(4): 801-807.

[19] GB/T 228-2002. Metallic materials-Tensile testing at ambient temperature. General Administration of Quality Supervision, Inspection and Quarantine of the People's Repulic of China, 2002.

[20] Ho JCM, Lai MH. Behaviour of uni-axially loaded CFST columns confined by tie bars. J Constr Steel Res 2013; 83: 37-50.

[21] Zhang DB, Nie X, Pan P, Wang MZ, Deng KL, Chen YB. Experimental study and finite element analysis of a buckling-restrained brace consisting of three steel tubes with slotted holes in the middle tube. J Constr Steel Res 2016; 124: 1-11.

[22] ABAQUS. ABAQUS standard user's manual, version 6.9. Providence, RI (USA): Dassault Systèmse Corp.; 2009. 
[23] GB 50010-2010. Code for design of concrete structures. Ministry of House and Urban-Rural Development of People's Republic of China, 2010.

[24] ACI 318-02. Building code requirements for reinforced concrete and commentary. Farmington Hills (MI), Detroit, USA: American Concrete Institute; 2002.

[25] Han LH, Yao GH, Tao Z. Performance of concrete-filled thin-walled steel tubes under pure torsion. Thin Wall Struct 2007; 45(1): 24-36.

[26] Ding FX, Yu ZW. Strength criterion for plain concrete under multiaxial stress based on damage poisson's ratio. Acta Mech Solida Sin 2006; 19(4): 307-315.

[27] Dai X, Lam D. Numerical modelling of the axial compressive behaviour of short concrete-filled elliptical steel columns. J Constr Steel Res 2010; 66(7): 931-942.

[28] Chang X, Wei YY, Yun YC. Analysis of steel-reinforced concrete-filled-steel tubular (SRCFST) columns under cyclic loading. Constr Build Mater 2012; 28(1): 88-95.

[29] Hu HT, Su FC. Nonlinear analysis of short concrete-filled double skin tube columns subjected to axial compressive forces. Mar Struct 2011; 24(4): 319-337.

[30] AIJ-1997. Recommendations for design and construction of concrete filled steel tubular structures. Architectural Institute of Japan, 1997.

[31] EC 4-1994. Design of steel and concrete structures, Part1, general rules and rules for building. British Standards Institution, 1994.

[32] AISC 360-2005. Load and resistance factor design (LRFD). Specification for structural steel buildings. American Institute of Steel Construction, 2005.

[33] GB 50936-2014. Technical Code for Concrete Filled Steel Tubular Structures. Ministry of House and Urban-Rural Development of People's Republic of China, 2014.

[34] Zhong ST. The concrete-filled steel tubular structures. Beijing: Tsinghua University Press, 2003.

[35] Cai SH. Modern concrete filled steel tube structure. Beijing: China Communications Press, 2007.

[36] Han LH, Yao GH. Experimental behaviour of thin-walled hollow structural steel (HSS) columns filled with self-consolidating concrete (SCC). Thin Wall Struct 2004, 42(9): 1357-1377.

[37] Zhang Y, Zhang Z. Study on equivalent confinement coefficient of composite CFST column based on unified theory. Mech Adv Mater Struc 2016; 23(1): 22-27.

[38] Kuranovas A, Goode D, Kvedaras AK, Zhong ST. Load-bearing capacity of concrete-filled steel columns. J Civ Eng Manag 2009; 15(1): 21-33.

[39] Cai SH, Jiao ZS. Behavior and ultimate strength of short concrete-filled steel tubular columns. J Build Struct 1984; 6(1): 13-28.

[40] Wang QX, Zhao DZ, Guan P. Experimental study on the strength and ductility of steel tubular columns filled with steel-reinforced concrete. Eng Struct 2004; 26(7): 907-915.

[41] Lai MH, Ho JCM. Confinement effect of ring-confined concrete-filled-steel-tube columns under uni-axial load. Eng Struct 2014; 67: 123-141. 